\section{Acute lower respiratory illness in under-five children in Rio Grande, Rio Grande do Sul State, Brazil: prevalence and risk factors}

\author{
Doença respiratória aguda baixa em menores de \\ cinco anos em Rio Grande, Rio Grande do Sul, \\ Brasil: prevalência e fatores de risco
}

\section{${ }^{1}$ Fundação Universidade Federal do Rio Grande, Rio Grande, Brasil. \\ 2 Fundação Faculdade Federal de Ciências Médicas de Porto Alegre, Porto Alegre, Brasil. \\ Correspondence S. O. M. Prietsch Fundação Universidade Federal do Rio Grande. Rua Dr. Nascimento 396 Rio Grande, RS 96200-300, Brasil. silvio@brturbo.com.br}

\begin{abstract}
This study aimed to determine the prevalence of acute lower respiratory illness and to identify associated factors among children less than five years of age in the city of Rio Grande, southern Brazil. Using a cross-sectional survey, a standardized household questionnaire was applied to mothers or guardians. Information was collected on household conditions, socioeconomic status, and parental smoking. Prenatal care attendance, nutritional status, breastfeeding pattern, and use of health services for the children were also investigated. Data analysis was based on prevalence ratios and logistic regression, using a conceptual framework. Among 771 children studied, 23.9\% presented acute lower respiratory illness. The main risk factors were previous episodes of acute lower respiratory infection or wheezing, crowding, maternal schooling less than five years, monthly family income less than US\$200, four or more people per room, asthma in family members, and maternal smoking. Mothers 30 years or older were identified as a protective factor. These results can help define specific measures to reduce morbidity and mortality due to acute lower respiratory illness in this setting.
\end{abstract}

Respiratory Tract Diseases; Child; Risk Factors

\author{
Silvio O. M. Prietsch 1 \\ Gilberto B. Fischer 2 \\ Juraci A. César 1 \\ Berenice S. Lempek 1 \\ Luciano V. Barbosa Jr. 1 \\ Luciano Zogbi 1 \\ Olga C. Cardoso 1 \\ Adriana M. Santos
}

\section{Introduction}

Risk factors have been identified for acute respiratory illness according to the following groups: demographic (gender and age), nutritional (low birth weight, malnutrition, inadequate breastfeeding, and vitamin and micronutrient deficiencies), and environmental (seasonality, crowding, air pollution, household pollution, and smoking), in addition to socioeconomic status, family history of respiratory illness, and prior illness 1 .

Acute respiratory infections are the main cause of utilization of health services by children under five in poor countries 2 . In terms of casefatality this represents 4 million deaths per year 3 . In Latin America, respiratory infections kill more than 80 thousand children per year, with $40 \%$ of these deaths occurring in Brazil 4. In the State of Rio Grande do Sul, Brazil, respiratory infections account for one-fourth of all deaths in children under five 5 .

In the extreme South of Brazil, where this study was performed, acute respiratory infections account for half of the medical consultations and hospitalizations in children under five years 6 .

This study aimed to measure the prevalence and identify the principal risk factors associated with acute lower respiratory illness in children under five years of age in the city of Rio Grande, Rio Grande do Sul State, Brazil. 


\section{Material and methods}

Rio Grande has a population of some 200 thousand and a local temperature ranging from $0^{\circ} \mathrm{C}$ in the winter to $36^{\circ} \mathrm{C}$ in the summer. The local economy is based on port, fishing, and petrochemical activities 7 .

This study included children 0 to 59 months of age, residing in the urban area of the municipality, from the months of August to November 1997. In order to achieve 5\% precision, $95 \%$ confidence level, and a beta error of 0.2 , information was needed on 771 children, according to the Epi Info statistical package, version 6.02 (Centers for Disease Control and Prevention, Atlanta, USA). An additional $10 \%$ was added to this figure to compensate for possible losses, plus $15 \%$ to control for confounding 8 .

A systematic cluster sample was used. This sample was based on the census tracts of the Brazilian Institute of Geography and Statistics, or National Census Bureau (IBGE; http://www.ibge. gov.br). A census tract includes a set of 200 to 300 households previously demarcated by the IBGE. The choice was made to work with one third of the urban census tracts, totaling 66 tracts (198/3). IBGE data estimated one child for every four households. Thus, to reach the desired sample size, it would be necessary to visit 47 households per tract $(47 \times 0.25 \times 66=775)$.

The first census tract was selected at random and the others by adding three to the previous one. Next, each block in these tracts was numbered, after which the block was picked. The corners were numbered by picking one corner, which was used as the starting point for visiting 47 consecutive households, always moving clockwise. When there were not enough households, the researchers moved on to the next block until reaching the desired number.

Fourteen medical and nursing and obstetrics undergraduate volunteers from the Federal University in Rio Grande were trained to apply standardized questionnaires to the mothers or guardians and weigh and measure the height or length of under-five children. Two types of questionnaires were used, one on the characteristics of the mothers and families and the other on the child. The questionnaires aimed at maternal demographic and reproductive information, sanitation and housing, socioeconomic status, use of health services, personal history of respiratory illnesses and wheezing, median breastfeeding duration, length or height, birth weight and current weight, and family history of respiratory illness.

To evaluate the intensity of association between sanitation and housing conditions and the target outcome, a score from 0 to 10 was cre- ated. A higher score indicated worse sanitation and housing conditions. The first step in creating the score was to dichotomize the variables representing the housing conditions in categories, "adequate" and "inadequate", according to data from the literature, followed by testing them for the outcome (acute lower respiratory illness). The category "adequate" was assigned a value of zero (corresponding to 0 points), while "inadequate" was assigned a value of one (corresponding to 1 point). The following were added to the housing conditions: crowding (persons/bedroom) and maternal smoking, also dichotomized in two categories (adequate and inadequate). Ten items thus comprised the "environmental score" variable. This new variable was tested in a parallel analysis model, replacing housing conditions, crowding, and smoking.

Acute lower respiratory illness was defined as a report of cough or respiratory difficulty (rapid or difficult breathing) with or without subcostal and/or intercostal retractions and requiring medical treatment in the previous seven days. For children under 12 months of age, the definition also included the presence of non-recurrent wheezing in the previous seven days 9,10,11.

Epi Info version 6.02 was used for the data entry, comparison of keying-in, and consistency analysis. SPSS version 8.0 (SPSS Inc., Chicago, USA) was used for the bivariate and multivariate analyses.

The analytical plan included the following stages: (1) obtaining a list of frequencies of all the variables (outcome, risk factors, and confounders) and examination of their distributions - when possible, the central trend (mean, median, and mode) and dispersal trends (range and standard deviation) were verified; (2) recoding, when necessary, with definition of the cutoff points for risk factors and confounding; (3) cross-analysis of independent variables with the outcome (acute lower respiratory illness). The magnitude of associations was estimated using the prevalence ratio (prevalence of exposed divided by prevalence of unexposed individuals) and $95 \%$ confidence interval (95\%CI). Calculation of the statistical significance of associations used the Pearson chi-squared test $\left(\chi^{2}\right)$, with Yates correction for variables with only two categories. For variables with more than two categories and logical ordering, the linear trend in proportions test was used; (4) possible associations were tested between variables that could confound the outcome with the risk factors; (5) finally, a multivariate analysis was performed, simultaneously controlling various risk and/or confounding factors, through the unconditional logistic regression method for obtaining prevalence ratios, and 
application of the goodness-of-fit test for obtaining statistical significance 12 . This analysis took into consideration a hierarchical model in which some variables are over-determinants of others, as proposed by Victora et al. 13 .

The proposed model presupposes that the target outcome varies according to the risk factors, because although some of them are not directly responsible for occurrence of the disease, they enhance the effect of other determinants. Demographic variables like gender, color, and age, although acting on the outcome, are not influenced by the other factors, although they can in principle be determinants of them. Socioeconomic status (SES) influences maternal reproductive characteristics and environmental factors, since it establishes exposure conditions. SES is thus included in the first level of the model's analysis, together with the demographic variables. The second level includes maternal characteristics and environmental factors, which can influence gestational and childbirth conditions. The third level includes prenatal and childbirth care, which can act on the child's birth conditions, growth monitoring, and nutritional status. This level also includes the use of preventive health services like vaccination and nutritional variables (birth weight, breastfeeding, and maternal nutritional status). The fifth level includes family history of respiratory illness, and the most proximal level of analysis includes personal history or prior illness. In this model, acting jointly or alone, these factors are decisive for the development (or lack thereof) of acute lower respiratory illness (Figure 1).

\section{Results}

We visited a total of 3,185 households in the 66 sampled census tracts, and identified 792 children; of these, 775 were included in the study, 13 were not located, and 4 refused to participate (losses $=2.1 \%$ ).

There was a slight predominance of children under three years of age and a nearly equal gender distribution. White children comprised 83\% of the sample. Half of the families had five or more members, and one third of the households with under-five children had two or more children in this age bracket. Seven percent of the mothers and $4 \%$ of the fathers could not read or write. Fifteen percent of the families had a monthly income of up to one hundred U.S. dollars (US\$ 100.00) and some $30 \%$ of the families had a monthly income of up to two hundred dollars (US\$200.00) in the month prior to the interview. Just over $70 \%$ lived in brick houses, and the rest were either wood or mixed (wood and brick), while $9 \%$ of the dwellings were made of tin plate, plastic, and/or cardboard. Virtually all the households had running water, and $90 \%$ had adequate sewage disposal. Thirty-seven percent of mothers and $40 \%$ of fathers smoked, and $60 \%$ of the households had at least one smoker. Sixty-two percent of the children had at least one prior episode of wheezing; of these, $51 \%$ had three or more episodes. Half of the children had some type of acute respiratory infection in the trimester prior to the interview; nearly half of them had an infection of the upper airways (acute upper respiratory infection), and $21 \%$ had an infection of the lower airways (acute lower respiratory infection). Approximately $10 \%$ of all the children had been hospitalized in the 12 months prior to the interview, with pneumonia as the principal cause $(60 \%)$.

The overall prevalence of acute lower respiratory illness was $23.9 \%$ (95\%CI: $21.1-26.9$ ). In the bivariate analysis, the following variables were significantly associated with acute lower respiratory illness: maternal schooling, paternal schooling, family income, maternal age, crowding (persons/room and persons/bedroom), maternal smoking, number of smokers in the household, smoking during pregnancy, unfavorable environmental score, mother's history of asthma, number of family members with asthma, history of acute respiratory infection, history of acute lower respiratory infection, hospitalization due to pneumonia, and prior episodes of wheezing. These variables were submitted to multivariate analysis together with those showing a p-value $\leq 0.20$. According to this criterion, the following variables were included: child's color, low birth weight, low weight-for-age, confirmed vaccination in infants ( $<12$ months), confirmed vaccination in children 12-24 months of age, and asthma in siblings.

Table 1 shows the variables introduced in the hierarchical model. Risk of acute lower respiratory illness was $65 \%$ greater for children of mothers with "lower schooling" as compared to children of mothers with $\geq 9$ complete years of schooling. For "paternal schooling”, after adjusting for the other variables at this level, there was a reduction in the prevalence ratios and a loss of statistical significance. The variable "family income" maintained an inverse linear relationship with respiratory illness: the higher the income, the lower the occurrence of acute lower respiratory illness, although the categorical goodnessof-fit test was not statistically significant. At the second level, "maternal age" and environmental variables were analyzed, showing a protective effect for children of mothers older than 30 at the time of the child's birth. Both "number of persons 
Summary of logistic analysis for acute lower respiratory illness.
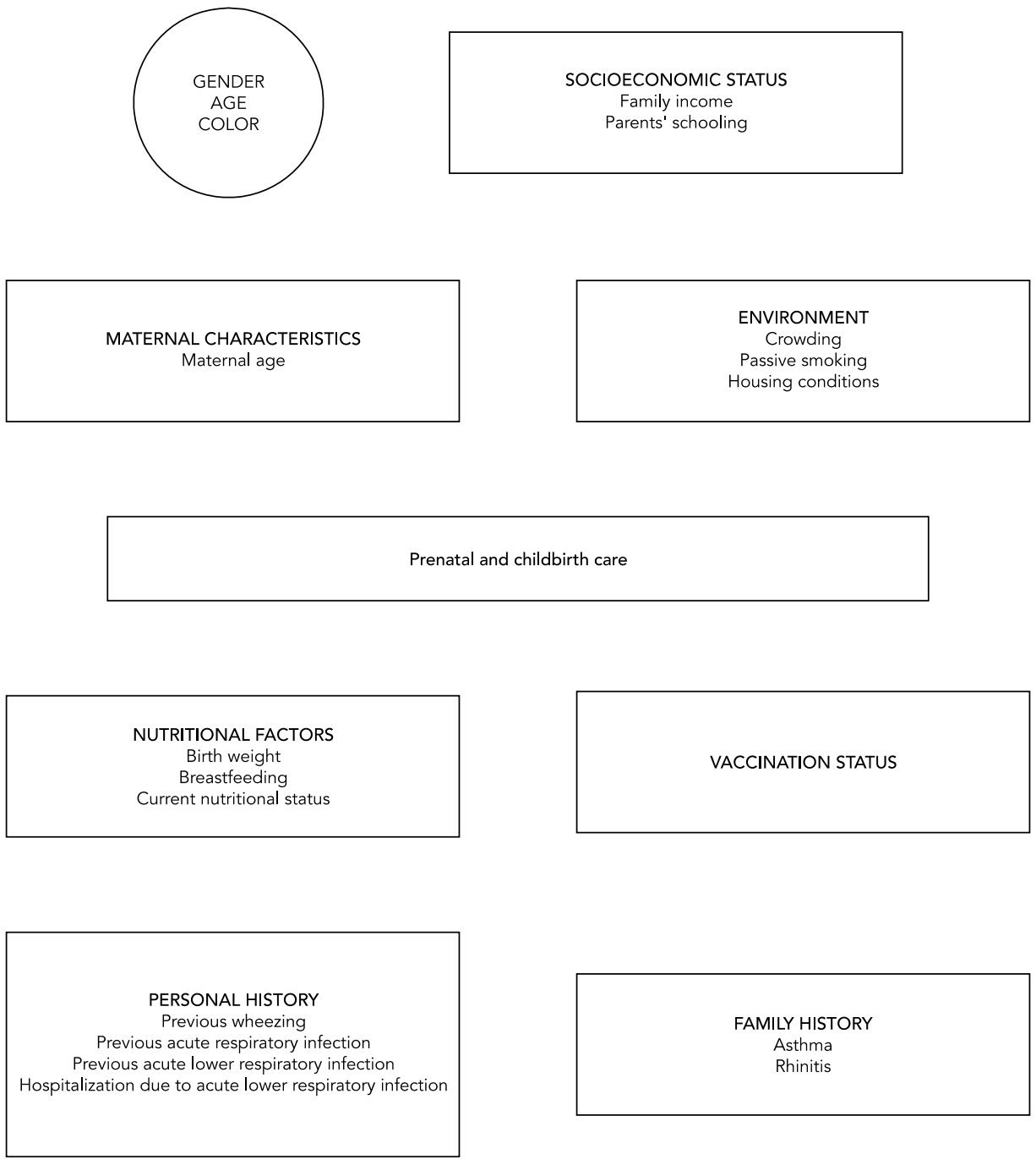

ACUTE LOWER RESPIRATORY ILLNESS (ALRI)

per bedroom" and "maternal smoking" were significantly associated with acute lower respiratory illness. "Maternal smoking" also showed a doseresponse effect.

The "environmental score" was introduced at the second level, together with "maternal age".
Figure 2 shows the results of the analysis for the "environmental score" variable, both crude and adjusted for socioeconomic factors and "maternal age". There was a direct association between the score and respiratory illness. Nutritional factors and vaccination status were analyzed at the 
Prevalence ratios and goodness-of-fit test for acute lower respiratory illness in children under five years of age. Bivariate and multivariate logistic regression analysis. Rio Grande, Rio Grande do Sul State, Brazil, 1997.

\begin{tabular}{|c|c|c|}
\hline \multirow[t]{2}{*}{ Variables (hierarchical model) } & \multicolumn{2}{|c|}{ Prevalence ratio $(95 \% \mathrm{Cl})$} \\
\hline & Crude & Adjusted \\
\hline Maternal schooling (complete years) & $p=0.01 * ; p<0.01 * *$ & $p=0.02 * ; p=0.01 * *$ \\
\hline $0-4$ & $1.70(1.18-2.44)$ & $1.65(1.15-2.37)$ \\
\hline $5-8$ & $1.49(1.04-2.12)$ & $1.47(1.04-2.08)$ \\
\hline$\geq 9$ & 1.00 & 1.00 \\
\hline Paternal schooling (complete years) & $p=0.06 * ; p=0.03 * *$ & $p=0.35 * ; p=0.22$ ** \\
\hline $0-4$ & $1.54(1.04-2.27)$ & $1.33(0.92-1.92)$ \\
\hline $5-8$ & $1.45(1.00-2.10)$ & $1.32(0.90-1.93)$ \\
\hline$\geq 9$ & 1.00 & 1.00 \\
\hline Family income (U.S. dollars) & $p<0.01 * ; p=0.001 * *$ & $p=0.12 * ; p=0.04$ ** \\
\hline$<200$ & $1.73(1.25-2.40)$ & $1.50(1.02-2.20)$ \\
\hline $200-500$ & $1.37(0.99-1.88)$ & $1.23(0.96-1.57)$ \\
\hline$\geq 500$ & 1.00 & 1.00 \\
\hline Maternal age at child's birth (years) & $p=0.08 * ; p=0.04 * *$ & $p=0.07 * ; p=0.05$ ** \\
\hline $13-19$ & $1.06(0.78-1.43)$ & $1.01(0.87-1.17)$ \\
\hline $20-29$ & 1.00 & 1.00 \\
\hline$\geq 30$ & $0.73(0.53-1.00)$ & $0.70(0.50-0.98)$ \\
\hline Crowding (persons/bedroom) & $p<0.01 * ; p=0.001 * *$ & $p=0.05 * ; p=0.02$ ** \\
\hline$\leq 2$ & 1.00 & 1.00 \\
\hline 3 & $1.43(1.03-1.99)$ & $1.33(0.96-1.85)$ \\
\hline$\geq 4$ & $1.72(1.23-2.41)$ & $1.54(1.08-2.19)$ \\
\hline Maternal smoking (cigarettes/day) & $p=0.03 * ; p<0.01 * *$ & $p=0.05 * ; p=0.01 * *$ \\
\hline Non-smoker & 1.00 & 1.00 \\
\hline $1-9$ & $1.33(0.89-1.99)$ & $1.22(0.80-1.86)$ \\
\hline$\geq 10$ & $1.43(1.09-1.87)$ & $1.41(1.07-1.86)$ \\
\hline Birth weight (grams) & $p=0.11$ * & $p=0.34$ * \\
\hline$\geq 2,500$ & 1.00 & 1.00 \\
\hline$<2.500$ & $1.43(0.98-2.10)$ & $1.24(0.80-1.92)$ \\
\hline Weight/age deficit & $p=0.20 * ; p=0.14 * \star$ & $p=0.33 * ; p=0.29 * *$ \\
\hline Normal weight & 1.00 & 1.00 \\
\hline Mild & $1.13(0.77-1.66)$ & $1.06(0.60-1.88)$ \\
\hline Moderate to severe & $1.96(1.01-3.79)$ & $1.87(0.82-4.27)$ \\
\hline Family member(s) with asthma & $p=0.001$ * & $p=0.01 *$ \\
\hline None & 1.00 & 1.00 \\
\hline$\geq 1$ & $1.53(1.19-1.97)$ & $1.46(1.11-1.92)$ \\
\hline Acute respiratory infection & $p=0.01 *$ & $p=0.01 *$ \\
\hline No & 1.00 & 1.00 \\
\hline Yes & $1.41(1.09-1.83)$ & $1.44(1.10-1.88)$ \\
\hline Acute lower respiratory infection & $p<0.001$ * & $p<0.0001$ * \\
\hline No & 1.00 & 1.00 \\
\hline Yes & $2.25(1.77-2.87)$ & $2.10(1.60-2.76)$ \\
\hline
\end{tabular}

* Categorical goodness-of-fit test;

** Linear trend goodness-of-fit test.

fourth level. There was no association between low birth weight and acute lower respiratory illness. However, this variable was maintained in the subsequent analyses since it is highly important in the theoretical investigative model.
For "family history of asthma", after adjusting for socioeconomic variables, "maternal age", environmental variables, and "birth weight", a statistical significance was observed, with a $50 \%$ greater risk when there was some family member with asthma. 


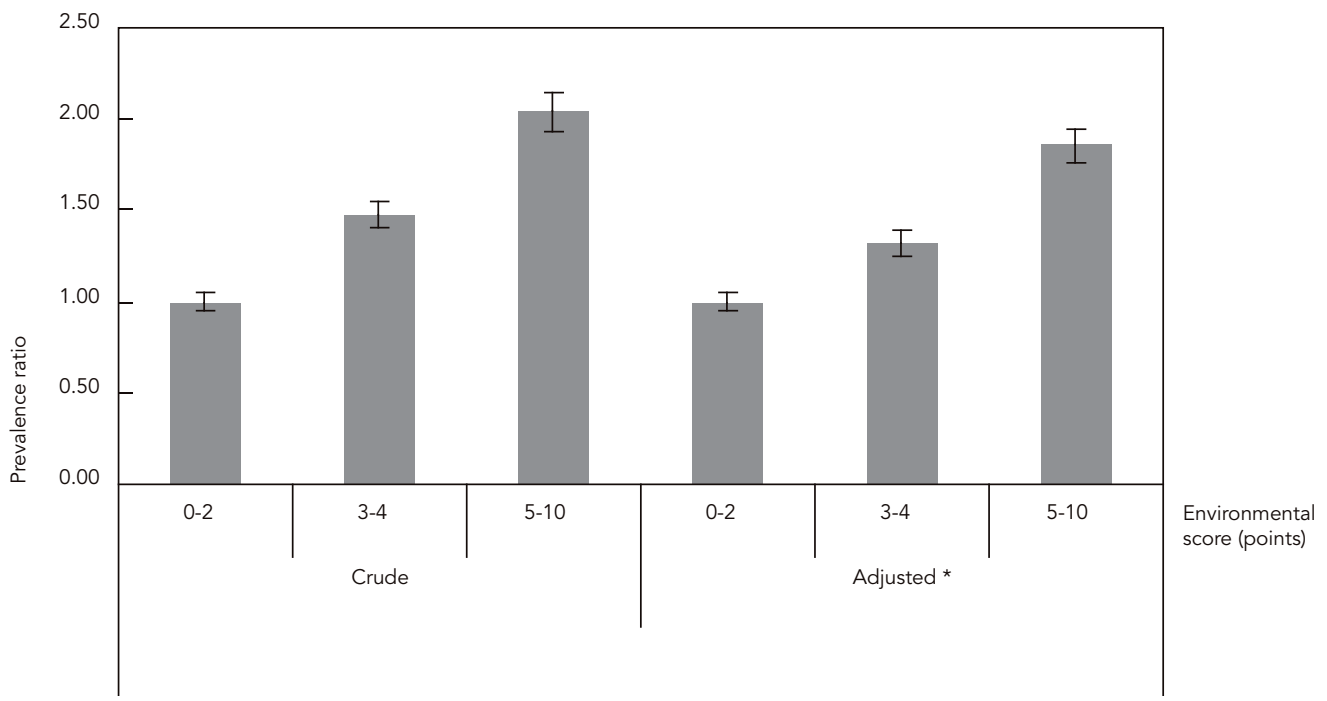

* Adjusted for maternal schooling, family income, and maternal age.

At the most proximal level of analysis, we tested the variables related to personal history of respiratory illness. There was an association between acute respiratory infection in the previous three months and current acute lower respiratory illness, even when adjusted for the other variables related to personal history (at the same level) and the hierarchically superior variables.

Higher reported number of wheezing episodes was associated with greater risk of current acute lower respiratory illness. The risk was twice as great for children with six or more episodes of wheezing as compared to children with two or fewer episodes of wheezing (Figure 3).

Table 2 summarizes the principal risk factors tested in relation to acute lower respiratory illness according to this study's hypotheses, organized in decreasing order of prevalence ratios. The values include controlling for potential confounders. The Table also shows the 95\% confidence intervals and risk factor prevalence in unexposed individuals.

\section{Discussion}

Prevalence of acute lower respiratory illness was quite high in the study sample. Prior episodes of respiratory infection and wheezing, household crowding, maternal smoking, precarious housing, and low maternal schooling were the main determinants of acute lower respiratory illness.

When discussing these results, it is important to keep in mind that the design adopted here is not the most adequate for measuring causality and that the diagnostic criterion shows high sensitivity and low specificity, which can overestimate occurrence of the disease. In relation to this possible overestimation of cases, it is very unlikely that it could explain or significantly change the high prevalence of acute lower respiratory illness. In addition, it is preferable to prepare health services to treat a case of bronchospasm as acute lower respiratory illness than to leave it as repressed demand. The time transpired between the data collection and publication of the article could be considered an important limitation. However, there was no important change during this period, either in the occurrence of the disease or in the supply of health care and management of acute respiratory illnesses in the municipality of Rio Grande. 
Risk of acute lower respiratory illness according to number of wheezing episodes. Rio Grande, Rio Grande do Sul State, Brazil, 1997.

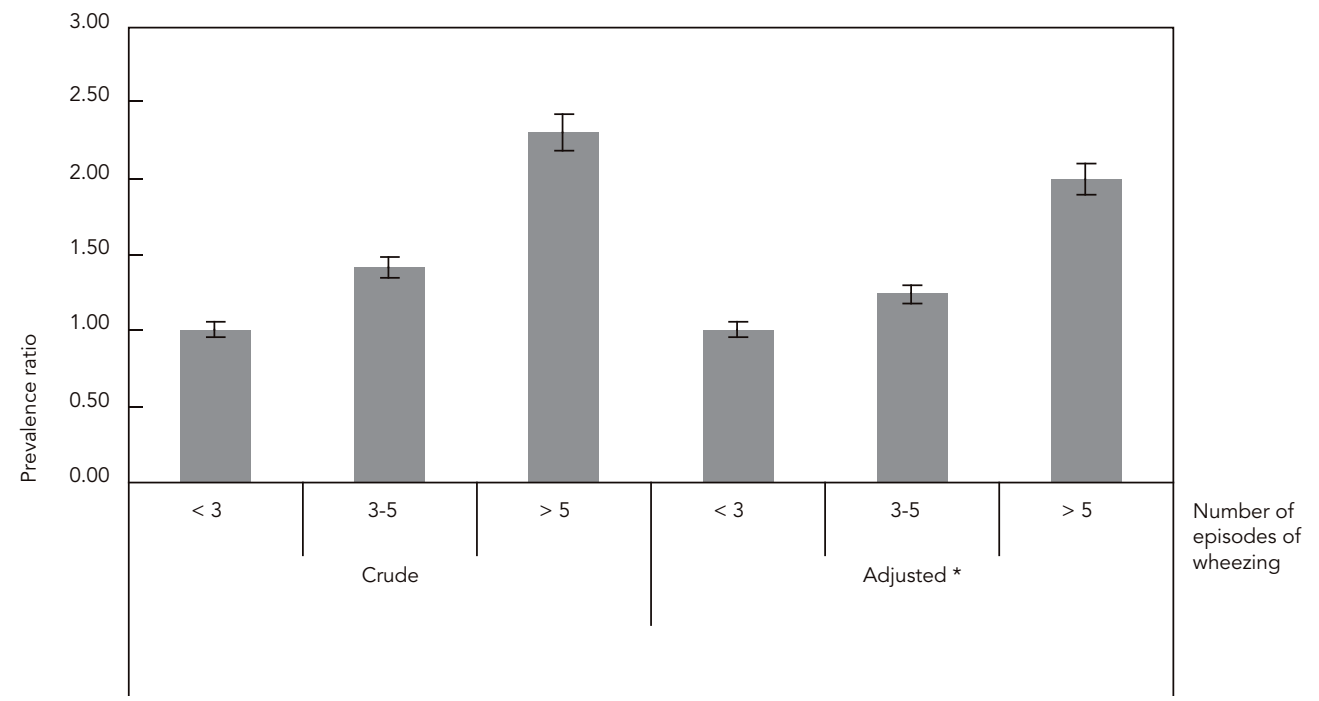

Note: $\mathrm{p}$-value for linear trend $<0.01$

* Adjusted for all the other variables in the model.

Summary of risk factors for acute lower respiratory illness in decreasing order of adjusted prevalence ratios. Rio Grande, Rio Grande do Sul State, Brazil, 1997.

\begin{tabular}{|c|c|c|c|}
\hline Risk factors & Prevalence in unexposed (\%) & Prevalence ratio & $95 \% \mathrm{Cl}$ \\
\hline Previous acute lower respiratory infection & 18.9 & 2.10 * & $1.60-2.74$ \\
\hline$\geq 6$ previous episodes of wheezing & 18.1 & 1.99 * & $1.23-3.22$ \\
\hline Moderate to severe low weight-for-age & 23.2 & $1.87 * \star$ & $0.82-4.27$ \\
\hline$\geq 5$ points on environmental score & 17.4 & $1.86 * \star \star$ & $1.27-2.73$ \\
\hline$\geq 20$ cigarettes/day during pregnancy & 17.2 & $1.74 \#$ & $0.74-4.00$ \\
\hline Maternal schooling $\leq 4$ years & 16.8 & $1.65 \# \#$ & $1.15-2.37$ \\
\hline$\geq 4$ persons/bedroom & 17.5 & 1.54 \#\#\# & $1.08-2.19$ \\
\hline Family income $<2$ times minimum wage & 17.9 & $1.50 \# \#$ & $1.02-2.20$ \\
\hline Family history of asthma & 19.3 & $1.46 \S$ & $1.11-1.92$ \\
\hline Previous acute respiratory infection & 19.6 & 1.44 * & $1.10-1.88$ \\
\hline Maternal smoking $\geq 10$ cigarettes/day & 20.8 & 1.41 \#\#\# & $1.07-1.86$ \\
\hline Paternal schooling $\leq 4$ years & 17.6 & $1.32 \# \#$ & $0.90-1.93$ \\
\hline Maternal age $\geq 30$ years & 25.7 & $0.70 \# \#$ & $0.50-0.98$ \\
\hline
\end{tabular}

* Model 6 = Model 2 + low birth weight + previous acute respiratory infection + previous acute lower respiratory infection + hospitalization due to pneumonia

+ previous wheezing;

** Model 4 = Model $2+$ low weight-for-age + low birth weight + confirmed vaccination;

*** Model 21 = Model $1+$ maternal age + environmental score;

\# Model 3 = Model $2+$ number of prenatal visits + number of cigarettes during pregnancy;

\#\# Model 1 = child's color + family income + paternal schooling + maternal schooling;

\#\#\# Model 2 = Model $1+$ maternal age + crowding + maternal smoking

$\S$ Model 5 = Model $2+$ low birth weight + maternal asthma + asthma in siblings + number of household members with asthma. 
In relation to the variables included in the analytical model, paternal schooling lost significance when it was adjusted for demographic variables and family income. This occurred because the father's schooling is almost always the principal determinant of family income 1. Family income maintained only a significant linear trend, and maternal schooling maintained an independent effect even after adjustment, thus reinforcing the idea that maternal schooling is the most important variable in the determination of health conditions and disease in early childhood 14 .

As in other studies, maternal age at the time of the child's birth showed an inverse association with acute lower respiratory illness, even when adjusted for socioeconomic and environmental factors, with a protective effect for maternal age of thirty years or more, showing that older mothers tend to care better for their children's health 15,16,17.

Although much of the effect of household crowding was confounded by environmental and socioeconomic variables, it is an important independent risk factor for acute lower respiratory illness (especially the number of persons sharing the children's bedroom) 11,18,19.

Two important aspects were observed with smoking: the high prevalence of smoking in this population and the risk posed by maternal smoking. After controlling for maternal age, other environmental variables, and socioeconomic status, maternal smoking remained statistically significant, thus reinforcing the risk, well documented in the literature, on the impact of passive smoking (especially from mothers) on children's respiratory health 20,21 .

There was a direct association between the score used to study the environmental variables and acute lower respiratory illness. Comparing the two models constructed for the analysis, the first with the environmental factors and the second with the "environmental score" variable replacing them, we observed no differences between them, even in relation to analysis of levels proximal to the outcome.

As shown in other studies, adverse environmental conditions represent an important risk factor for acute respiratory illnesses in children 11,22 . No significant association was found between low birth weight and acute lower respiratory illness, although the prevalence of acute lower respiratory illness was $10 \%$ higher in low birth weight children as compared to others. An association between low birth weight and severe respiratory illness has been widely described 1,23. Contrary to findings in Kenya 24 , India 25, and other poor countries 26 , our study did not show a significant association between acute lower respiratory illness and nutritional deficit. However, acute lower respiratory illness was much more frequent in children with a moderate to severe deficit in the three indicators (weight-for-age, weight-for-height, and height-for-age). Importantly, based on the calculated indicators, the prevalence of nutritional deficit in this population was quite low, with less than $1.5 \%$ prevalence of moderate to severe weight-for-age deficit. Nor was any association observed between breastfeeding duration and acute lower respiratory illness, although this has been demonstrated clearly, specifically for pneumonia 15,27,28. There was an important association between acute lower respiratory illness and previous episodes of acute respiratory infections in general, acute lower respiratory infections, and hospitalization due to pneumonia. The risk of presenting acute lower respiratory illness for children with a previous history of acute lower respiratory infection was twice as great for children with previous episodes of wheezing, and the increase in the risk of acute lower respiratory illness was directly associated with the number of episodes. These findings confirm others already described in the literature as to the presence of previous illness 11,18,29,30.

The data in this study show that children with a personal history of respiratory diseases constitute a high-risk group. Preventive measures and early interventions should focus on these children as a priority.

There is an evident need to reduce socioeconomic risks like household crowding and childhood malnutrition, as well as environmental risks like maternal smoking, in order to reduce both the number and severity of cases of acute lower respiratory illnesses. The current study thus helps provide a better understanding of the events linked to these diseases at the local level and the basis for establishing specific programs for their control. 


\section{Resumo}

Este estudo teve por objetivo determinar a prevalência de doenças respiratórias agudas baixas e identificar fatores associados à sua ocorrência entre crianças menores de cinco anos de idade em Rio Grande, Rio Grande do Sul, Brasil. Realizou-se estudo transversal de base populacional com aplicação de questionário em nível domiciliar às mães ou responsáveis pelas crianças. Foram coletadas informações sobre características sócio-econômicas, condições de habitação da família e tabagismo dos pais; sobre as crianças, investigou-se padrão de amamentação e dieta, estado nutricional, assistência à gestação e ao parto e utilização de serviços de saúde. A análise incluiu cálculo das razões de prevalência e regressão logística conforme modelo hierárquico previamente estabelecido. Dentre as 771 crianças estudadas, 23,9\% apresentavam doenças respiratórias agudas baixas. Os principais fatores de risco identificados foram antecedente de infecção respiratória, sibilância anterior, aglomeração, escolaridade materna menor que cinco anos, renda familiar menor que dois salários mínimos mensais, quatro ou mais pessoas no quarto da criança, história de asma na família e tabagismo materno. Idade materna igual ou superior a trinta anos mostrou-se protetor. Esses resultados podem contribuir para estabelecer medidas específicas visando a reduzir a morbimortalidade por doenças respiratórias agudas baixas nessa população.

Doença Respiratória; Criança; Fatores de Risco

\section{Contributors}

S. O. M. Prietsch participated in the coordination of the research and final drafting of the article. G. B. Fischer oriented the research and drafted the article. J. A. César collaborated in the data analysis and drafting and systematization of the article and was responsible for writing the abstract. L. V. Barbosa Jr. contributed with the supervision of the fieldwork, review of the data collection, and drafting of the article. B. S. Lempek and L. Zogbi contributed with the literature review and systematization of the article. O. C. Cardoso and A. M. Santos collaborated with keying in the data and manuscript.

\section{Acknowledgments}

Financing for this study was provided by the Municipal Health Department of Rio Grande, Rio Grande do Sul State, Brazil.

\section{References}

1. Victora CG. Factores de riesgo en las IRA bajas. In: Benguigui Y, Lópes-Antuñano FJ, Yunes J, editores. Infecciones respiratorias en niños. Washington DC: Pan American Health Organization; 1996. p. 45-63.

2. Schmunis G. Prólogo. In: Benguigui Y, organizador. Investigações operacionais sobre o controle das infecções respiratórias agudas (IRA). Washington DC: Pan American Health Organization; 1997. p. iii.

3. Benguigui Y. Controle das infecções respiratórias agudas: implementação, acompanhamento e avaliação. v. 2. Washington DC: Pan American Health Organization; 1997.
4. Arias SJ, Benguigui Y, Bossio JC. Infecciones respiratorias agudas en las Américas: magnitud, tendencia y avances en el control. Washington DC: Pan American Health Organization; 1992.

5. Secretaria de Saúde e do Meio Ambiente do Rio Grande do Sul. Estatísticas de saúde: mortalidade 2000. v. 25. Porto Alegre: Secretaria de Saúde e do Meio Ambiente do Rio Grande do Sul; 2001.

6. César JA, Horta BL. Desigualdade e perversidade: epidemiologia do adoecer no extremo-sul do Brasil. Rio Grande: Editora da FURG; 1997.

7. Barros AJD, Victora CG. Indicador econômico para o Brasil baseado no censo demográfico de 2000. Rev Saúde Pública 2005; 39:523-9. 
8. Smith PG, Day NE. The design of case-control studies: the influence of confounding and interaction effects. Int J Epidemiol 1984; 13:356-65.

9. Ferris BG. Epidemiology Standardization Project (American Thoracic Society). Am Rev Respir Dis 1978; 118(6 Pt 2):1-120.

10. World Health Organization. Programme for control of acute respiratory infections: definitions of clinical signs and symptoms. Interim Programme Report - Draft 1988. Geneva: World Health Organization; 1988.

11. Victora CG, Fuchs SC, Flores JAC, Fonseca W, Kirkwood BR. Risk factors for pneumonia among children in a Brazilian metropolitan area. Pediatrics 1994; 93:977-85.

12. Rothman KJ. Modern epidemiology. Boston: Little, Brown and Co.; 1986.

13. Victora CG, Huttly SR, Fuchs SC, Olinto MTA. The role of conceptual frameworks in epidemiological analysis: a hierarchical approach. Int J Epidemiol 1997; 26:224-7.

14. Victora CG, Barros FC, Vaughan JP. Epidemiologia da desigualdade: um estudo longitudinal de 6.000 crianças brasileiras. 2a Ed. São Paulo: Editora Hucitec; 1988.

15. Victora CG, Smith PG, Barros FC, Vaughan JP, Fuchs SC. Risk factors for deaths due to respiratory infections among Brazilian infants. Int J Epidemiol 1989; 18:918-25.

16. Fonseca WVC. Risk factors for childhood pneumonia among the poor urban in Fortaleza, Brazil: a case-control study [Doctoral Dissertation]. London: London School of Hygiene and Tropical Medicine; 1993.

17. Klig JE, Shah NB. Office pediatrics: current issues in lower respiratory infections in children. Curr Opin Pediatr 2005; 17:111-8.

18. Cardoso MR, Cousens SN, Góes Siqueira LF, Alves FM, D'Angelo LA. Crowding: risk factor or protective factor for lower respiratory disease in young children? BMC Public Health 2004; 4:19.

19. Prietsch SO, Fischer GB, César JA, Lempek BS, Barbosa Jr. LV, Zogbi L, et al. Respiratory illnesses in children younger than 5 years of age in southern Brazil: the influence of the home environment. Rev Panam Salud Pública 2003; 13:303-10.
20. Environmental tobacco smoke: a hazard to children. American Academy of Pediatrics Committee on Environmental Health. Pediatrics 1997; 99: $639-42$.

21. Gonçalves-Silva RM, Valente JG, Lemos-Santos MG, Sichieri R. Tabagismo no domicílio e doença respiratória em crianças menores de cinco anos. Cad Saúde Pública 2006; 22:579-86.

22. Lopez Bravo IM, Sepulveda H, Valdes I. Acute respiratory illnesses in the first 18 months of life. Rev Panam Salud Pública 1997; 1:9-17.

23. Menezes AM, Hallal PC, Santos IS, Victora CG, Barros FC. Infant mortality in Pelotas, Brazil: a comparison of risk factors in two birth cohorts. Rev Panam Salud Pública 2005; 18:439-46.

24. Ballard TJ, Neumann CG. The effects of malnutrition, parental literacy and household crowding on acute lower respiratory infections in young Kenyan children. J Trop Pediatr 1995; 41:8-13.

25. Deb SK. Acute respiratory disease survey in Tripura in case of children below five years of age. J Indian Med Assoc 1998; 96:111-6.

26. Selwyn BJ. The epidemiology of acute respiratory tract infection in young children: comparison of findings from several developing countries. Coordinated Data Group of BOSTID Researches. Rev Infect Dis 1990; 12 Suppl 8:S870-88.

27. Wright AL, Bauer M, Naylor A, Sutcliffe E, Clark L. Increasing breastfeeding rates to reduce infant illness at the community level. Pediatrics 1998; 101:837-44.

28. César JA, Victora CG, Barros FC, Santos IS, Flores JA. Impact of breastfeeding on admission for pneumonia during postneonatal period in Brazil: nested case-control study. BMJ 1999; 318:1316-20.

29. Dinwiddie R. O diagnóstico e o manejo da doença respiratória pediátrica. Porto Alegre: Editora Artes Médicas; 1992

30. Phelan PD, Olinsky A, Robertson CF. Respiratory illness in children. 4th Ed. Melbourne: Blackwell Scientific Publication; 1994.

Submitted on $12 /$ Jun/2006

Final version resubmitted on $03 / \mathrm{Sep} / 2007$

Approved on 08/Oct/2007 